\title{
A prosódia e a leitura fluente
}

Gessiane Lobato Picanço ${ }^{a}$

Nair Sauaia Vansiler ${ }^{b}$

\begin{abstract}
Resumo
A leitura expressiva é uma maneira de o leitor demonstrar os significados apreendidos do texto. Portanto, a expressividade na leitura oral pode não só distinguir entre leitores mais e menos habilidosos, mas também pode ser usada para monitorar a compreensão. Leitores fluentes incorporam características prosódicas da língua falada (acentuação, variações de altura de voz, entonação, fraseado e pausas) durante a leitura, fazendo-a soar o mais natural possível. Esta pesquisa mostra a avaliação de três dimensões prosódicas, entonação e ênfase, fraseado e ritmo, na leitura realizada por alunos do $2^{\circ}$ ano do ensino médio de quatro escolas públicas de Belém, estado do Pará. Os resultados apontam para uma grave deficiência no ensino da língua portuguesa no ensino médio: a maioria dos alunos ainda não alcançou um nível minimamente aceitável de fluência. ${ }^{1}$
\end{abstract}

Palavras-chave: Fluência. Expressividade oral.

${ }^{1}$ Pesquisa vinculada Leitura. Avaliação da leitura. ao Projeto "Proficiência em Leitura", processo No. 487139/2012-7 / CNPq, coordenado pela Dra. Gessiane Lobato Picanço. Agradecemos às escolas e alunos que participaram voluntariamente da pesquisa; também a Cláudio Rui dos Santos e Silva pela imensa ajuda com as análises estatísticas.

${ }^{a}$ UFPA - Universidade Federal do Pará, Instituto de Letras e Comunicação. Pará, Belém, BR. picanco.g@hotmail.com

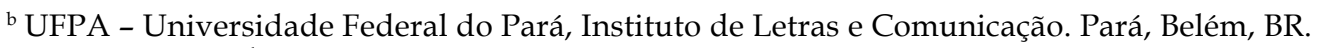
nairsauaia@gmail.com 


\section{Introdução}

As pesquisas sobre fluência em leitura têm chamado muito a atenção para a importância do desenvolvimento de três habilidades (PINNELL et al., 1995; NRP, 2000, entre outros): a habilidade para decodificar corretamente as palavras no texto (precisão); a habilidade para decodificar palavras no texto com o mínimo de esforço e rapidez (velocidade); e a habilidade para aplicar adequadamente os traços prosódicos à leitura das sentenças e parágrafos (expressividade). Precisão e automaticidade na decodificação de palavras já são, desde longa data, consideradas aptidões essenciais em uma leitura proficiente: quanto menos atenção o leitor dispensar à decodificação, mais ela será direcionada para a compreensão do material lido (LaBERGE; SAMUELS, 1974; STANOVICH, 1980; ADAMS, 1990; FUCHS et al., 2001, etc.).

A expressividade, por sua vez, vem sendo cada vez mais reconhecida não só como uma marca capaz de distinguir um leitor habilidoso de outro menos habilidoso, mas também como um pré-requisito para a compreensão (ALLINGTON, 1983; DOWHOWER, 1991; KUHN; STAHL, 2003; PAIGE et al., 2012). Nas palavras de Paige et al. (2012, p. 67):

Leitores fluentes tendem a ler de uma forma a construir o significado, ao passo que leitores menos fluentes tendem a fazer um grande esforço para chegar ao sentido. [...] Uma prosódia pobre pode levar à confusão através de agrupamentos inapropriados ou sem sentido das palavras. ${ }^{2}$

${ }^{2}$ Texto original: "Fluent readers tend to read in a way that constructs meaning, whereas less-fluent readers tend to struggle with making meaning. [...] Poor prosody may lead to confusion through inappropriate or meaningless groupings of words."
O foco deste estudo será em leitura expressiva, a qual, segundo Kuhn e Stahl (2003), refere-se ao agrupamento adequado das palavras em unidades maiores de significado (frases ou sentenças), obedecendo à sintaxe original do texto; também deve soar, sempre que possível, tão natural quanto a língua falada, ou seja, o leitor deve fazer uso apropriado da estrutura entoacional da língua, com pausas e ênfases em locais específicos, e mantendo um ritmo conversacional consistente (ZUTTELL; RASINSKI, 1991; FOUNTAS; PINNELL, 2006). Leitores fluentes incorporam características prosódicas ou melódicas da língua falada - acentuação, variações de altura de voz, entonação, fraseado, e pausas. Essa incorporação da prosódia mostra que o leitor está tentando compreender o texto (CAGLIARI, 1992). 
Essa não é uma tarefa fácil, pois são poucas as informações prosódicas que o leitor tem à sua disposição em um texto escrito, e parcialmente sinalizadas através dos sinais de pontuação e alguns sinais gráficos, como no trecho a seguir, retirado de um livro didático do ensino médio. Além da pontuação básica (vírgulas e pontos), os autores destacam, pelo uso de aspas, somente algumas palavras.

Segundo o Aurélio, o advérbio "nunca" significa "em tempo algum; jamais". Eu acho essa palavra uma das mais fortes e mais perigosas da Língua portuguesa. Porque ninguém pode afirmar com propriedade que nunca vai agir de uma certa forma - o futuro vive nos pregando peças. Também é cruel responder assim a alguém que possui uma certa expectativa de resposta afirmativa. (ABAURRE et al., 2008, p. 473)

Enquanto o texto consegue guiar o leitor em relação ao agrupamento de palavras em unidades sintáticas maiores, deixa a desejar em relação a outros aspectos da prosódia entonação, ênfases e ritmo. O exemplo abaixo ilustra a leitura realizada por um leitor fluente. Cada linha numerada contém uma unidade entoacional, termo empregado por Chafe (1988) para designar o seguimento de palavras agrupadas em um único contorno entoacional; as palavras capitalizadas marcam as ênfases dadas a palavras específicas, e as reticências marcam pausas breves dentro do mesmo grupo de entonação. Como se pode observar, esse leitor empregou a ênfase em várias palavras, além do que estava sinalizado no texto original. Além disso, a entonação não precisa corresponder à pontuação utilizada pelo autor como, por exemplo, na sentença 'o futuro vive nos pregando peças', cuja entonação dada pelo leitor corresponderia à de um ponto de exclamação.

1 - Segundo o AURÉLIO ... o advérbio NUNCA ... significa em tempo algum ... JAMAIS.

2 - Eu acho essa palavra uma das mais FORTES e mais PERIGOSAS da lingua portuguesa.

3 - Porque NINGUÉM pode afirmar com PROPRIEDADE ... que NUNCA vai agir de uma certa forma.

4 - O futuro vive nos pregando peças!

5 - Também é CRUEL responder assim a alguém que possui uma CERTA expectativa de resposta afirmativa. 
O próximo exemplo ilustra uma leitura menos expressiva. A leitura é caracterizada, grosso modo, por um número maior de grupos entoacionais, excesso de pausas dentro desses grupos, desvios da sintaxe original do texto, poucas ênfases, quase nenhuma alteração na altura da voz (leitura monotônica), e um padrão rítmico inconsistente, alternando entre leitura lenta (linhas 1, 3 e 5) e rápida (linhas 4 e 6).

1 - Segundo o Aurélio ... o advérbio ... NUNCA ... significa ... em tempo algum.

2 - Em tempo algum ... jamais.

3 - Eu acho que essa palavra ... uma das mais fortes e mais perigosas ... da língua portuguesa.

4 - Porque ninguém pode afirmar com propriedade que nunca vai agir ... de uma certa forma.

5 - O futuro vive nos pregando ... PEÇAS ... também ... e cruel responder ansim.

6 - A alguém que possui uma carta expectativa ... de resposta afirmativa.

O restante deste artigo apresenta os resultados de uma avaliação da expressividade oral na leitura realizada com alunos do ensino médio de escolas públicas de Belém, estado do Pará. A seção seguinte dá os detalhes dos procedimentos metodológicos adotados na pesquisa e, em seguida, apresentaremos os resultados e suas implicações para o ensino/aprendizagem da língua portuguesa.

\section{Procedimentos metodológicos}

Conforme discutido acima, a leitura expressiva é uma maneira de o leitor demonstrar os significados apreendidos do texto. Para análise desse elemento, faz-se necessário a transcrição da leitura do aluno e posterior avaliação para que, assim, essa última não seja dada somente pelas impressões pessoais do professor ou pesquisador. Por isso, quando os fatos podem ser quantificados e representados graficamente, não só é possível descrever o nível atual de desempenho do aluno, como também estimar, com maior segurança, sua taxa de crescimento. O Curriculum-based measurement (DENO, 1985) oferece 
um modo eficaz para a realização desse tipo de medição, uma vez que produz uma estatística que descreve o crescimento do estudante no currículo da própria escola. Seus procedimentos básicos envolvem gravar um minuto de leitura em voz alta de trechos de textos previamente selecionados e compatíveis com a série examinada. Esses textos foram padronizados de acordo com os seguintes critérios: conter entre 200 e 250 palavras; ser equivalente à série em curso; conter assuntos previstos no conteúdo programático da série e ser considerado de fácil leitura, ou seja, com palavras de uso mais rotineiro.

As amostras de leitura foram coletadas entre os meses de maio e junho do corrente ano. Quatro escolas públicas do $2^{\circ}$ ano do Ensino Médio de Belém, no estado do Pará, e 42 alunos participaram voluntariamente da pesquisa, sendo que cada aluno contribuiu com três leituras, gerando assim um corpus de 126 amostras analisadas ${ }^{3}$. Todas as leituras foram realizadas individualmente e as amostras foram transcritas e analisadas posteriormente.

\section{Escala multidimensional de fluência em leitura}

A análise quantitativa das amostras de leitura foi realizada com base nos parâmetros de expressividade oral de uma escala multidimensional, adaptada a partir das propostas de Fountas e Pinnell (2006), Rasinski (2004) e Zuttell e Rasinski (1991) para esta pesquisa. Nessa perspectiva, a leitura expressiva é avaliada de acordo com suas três dimensões: entonação e ênfase, fraseado e fluidez no ritmo. Cada dimensão pode ser avaliada independentemente em quatro níveis, representados pelos valores de 1 a 4, que descrevem o grau de fluência em expressividade oral, como detalhado a seguir.

Entonação e ênfase: referem-se ao modo como o leitor usa a variação na voz (tom, altura e volume) para refletir o significado do texto. O desempenho dos alunos nessa dimensão foi avaliado de acordo com as seguintes características (FOUNTAS; PINNELL, 2006; RASINSKI, 2004):

${ }^{3}$ Houve uma leitura inicial que serviu como treino para que os alunos se familiarizassem com os procedimentos da pesquisa. Essas amostras não foram incluídas na análise.
- Nível 1 = Quase nenhuma variação na voz: o leitor não utiliza a expressividade, lendo o texto sem entusiasmo na voz (monotônico), ou seja, lê as palavras simplesmente por ler; há pouco esforço para fazer o texto soar como língua natural e a tendência é ler em 
voz baixa, sem ênfase alguma em certas palavras para refletir o significado.

- Nível 2 = Pouca evidência de variação na voz: demonstra expressividade em algumas partes do texto, onde utiliza a expressividade para fazer a leitura soar como língua natural, contudo continua apenas pronunciando as palavras; ainda lê com voz baixa, mas já começa a utilizar alguma ênfase em palavras para refletir o significado do texto.

- Nível 3 = Alguma evidência de variação na voz: o leitor lê de forma natural em boa parte do texto, embora ainda tenda a uma leitura inexpressiva em alguns momentos; o volume de voz é geralmente apropriado na maior parte do texto e apresenta ênfase em alguns trechos ou palavras.

- Nível 4 = Quase toda a leitura é caracterizada pela variação na voz: lê com boa expressividade e entusiasmo; soa como língua natural na maior parte da leitura; é capaz de variar a expressão e o volume da voz para dar ênfase de acordo com sua interpretação do trecho.

Outra dimensão que distingue leitores mais ou menos habilidosos é o fraseado, que se refere ao modo como o leitor agrupa as palavras do texto para representar unidades maiores de significado, as unidades entoacionais. A leitura deve obedecer à sintaxe original do texto e soar como a língua falada, embora mais formal. A avaliação dessa dimensão é baseada nos seguintes aspectos (adaptado de FOUNTAS; PINNELL, 2006; ZUTTELL; RASINSKI, 1991, p.215):

- Nível 1 = Quase não preserva a sintaxe original do texto: o leitor tem pouca noção de fronteiras de frases, sentenças e orações; ainda exibe leitura "palavra por palavra", sem atentar para a pontuação, ênfases ou entonação.

- Nível 2 = Preserva um pouco da sintaxe original do texto: lê em frases maiores (três a cinco palavras) na maior parte do tempo, porém tem dificuldade em reconhecer fronteiras de frases, sentenças e orações, usando indevidamente a entonação, sem se autocorrigir. 
- Nível 3 = Controle maior da sintaxe original do texto: consegue ler em unidades maiores, respeitando grande parte da pontuação; apresenta ainda dificuldades em reconhecer fronteiras de frases, sentenças e orações, mas consegue se autocorrigir algumas vezes; a ênfase e entonação são razoáveis e usadas para marcar as fronteiras de grupos entoacionais maiores.

- Nível 4 = Preserva quase toda a sintaxe original do texto: o leitor respeita, principalmente, as unidades das cláusulas e sentenças, com a devida atenção à expressividade; quase toda a leitura reflete a pontuação e o significado do texto; erros podem ocorrer, mas são imediatamente corrigidos na maioria das vezes. Soma-se a isso o fato da leitura soar como língua natural.

Quanto à fluidez no ritmo, o leitor fluente lê de forma natural, com padrão rítmico consistente e o mínimo de dificuldade. Assim, pode-se identificar, com relação ao padrão rítmico da leitura, as seguintes características (adaptado de ZUTTELL; RASINSKI, 1991, p.215):

- Nível 1 = Ritmo lento e trabalhoso: o leitor exibe várias interrupções extensas, hesitações, falsos começos, dúvidas na leitura de palavras, repetições e/ou múltiplas tentativas.

- Nível 2 = Ritmo moderadamente lento: encontra vários pontos difíceis no texto, onde ocorrem interrupções (algumas prolongadas), hesitações, repetições, etc., de forma frequente e desordenada.

- Nível 3 = Ritmo com mistura de leitura rápida e lenta: faz interrupções ocasionais, porém causadas por dificuldades com palavras e/ou estruturas específicas.

- Nível 4 = Ritmo conversacional consistente: lê de uma forma natural, com o mínimo de interrupções; as dificuldades com palavras e estruturas específicas são resolvidas rapidamente, sem quebrar o ritmo da leitura e, geralmente, através de autocorreção. 
As amostras de leitura são analisadas individualmente de acordo com os níveis acima descritos. Para se obter o nível final de fluência em expressividade oral de cada aluno, calcula-se a média geral a partir das pontuações obtidas em cada dimensão, conforme ilustrado na Tabela 1. Essa quantificação também permite avaliar o desempenho da escola como um todo, calculando-se sua média a partir das médias alcançadas pelos alunos.

\begin{tabular}{|c|c|c|c|c|c|c|c|c|c|c|}
\hline ALUNO & \multicolumn{3}{|c|}{ ENTONAČÃO E ÊNFASE } & \multicolumn{3}{|c|}{ FRASEADO } & \multicolumn{2}{|c|}{ FLUIDEZ NO RITMO } & NÍVEL FINAL \\
\hline & $\begin{array}{c}\text { TXT } \\
01\end{array}$ & $\begin{array}{c}\text { TXT } \\
02\end{array}$ & $\begin{array}{c}\text { TXT } \\
03\end{array}$ & $\begin{array}{c}\text { TXT } \\
01\end{array}$ & $\begin{array}{c}\text { TXT } \\
02\end{array}$ & $\begin{array}{c}\text { TXT } \\
03\end{array}$ & $\begin{array}{c}\text { TXT } \\
01\end{array}$ & $\begin{array}{c}\text { TXT } \\
02\end{array}$ & $\begin{array}{c}\text { TXT } \\
03\end{array}$ & \\
\hline AF & 4 & 3 & 4 & 4 & 3 & 4 & 3 & 3 & 4 & $\mathbf{3 , 5}$ \\
\hline EHC & 3 & 2 & 1 & 3 & 3 & 3 & 3 & 3 & 3 & $\mathbf{2 , 6}$ \\
\hline GLF & 3 & 2 & 3 & 2 & 2 & 2 & 2 & 3 & 3 & $\mathbf{2 , 4}$ \\
\hline
\end{tabular}

Tabela 01: Cálculo das médias de fluência por aluno e por escola. Fonte: Projeto Fluência em leitura, 2013

O nível final refere-se ao modo como o leitor integra as três dimensões, pois seu desempenho é variável, dependendo não só de cada dimensão como do tipo de texto lido. Por exemplo, o aluno AF alcançou o nível 4 em entonação/ênfase e fraseado nos textos 01 e 03 , mas obteve 3 no texto 02 ; já em relação ao ritmo, $\mathrm{AF}$ alcançou 3 na maioria dos textos lidos. Sua média geral é, portanto, 3,5. Esse resultado final indica o desempenho do aluno ao integrar todas as dimensões. Tal integração revela se o aluno possui uma leitura não fluente, pouco fluente ou fluente, da seguinte forma:

Média de 1 a 2 = leitura não fluente: leitura é monotônica e inexpressiva, com ritmo lento e trabalhoso; há muitos erros no agrupamento de palavras e muitas pausas em locais inadequados, hesitações, repetições, dúvidas ou erros na leitura de palavras, etc., com perdas no significado geral do texto; autocorreção é rara ou ausente.

Média de 2,1 a 3 = leitura pouco fluente: pode oscilar entre leitura expressiva e inexpressiva, rápida e lenta; demonstra alguma atenção à pontuação e à sintaxe do texto, mas ainda exibe erros em agrupamentos de palavras e algumas pausas indevidas, hesitações e repetições; há poucos ajustes na entonação para transmitir o significado; autocorreção é eventual. 
Média de 3,1 a 4 = leitura fluente: leitura é feita em grandes unidades sintáticas (sentenças e orações), respeitando a pontuação e a sintaxe originais do texto; há ajustes na entonação de modo a refletir o significado na maior parte do texto; o leitor mantém um bom ritmo na leitura de modo a soar como língua natural e quase sempre se automonitora quanto aos deslizes, corrigindo-os imediatamente.

\section{Análise das transcrições}

Nesta seção discutimos os procedimentos da análise das transcrições. Determinaram-se, primeiramente, as unidades entoacionais sinalizadas no texto original, de acordo com a pontuação utilizada pelo autor. Em seguida, destacaram-se as prováveis ênfases em palavras específicas, se essas já não estivessem indicadas originalmente no texto. No trecho escolhido para ilustração, há três grupos entoacionais marcados pelas pontuações no texto original, conforme mostrado abaixo. Como o trecho não contém nenhuma indicação de ênfase, destacamos também diferentes possibilidades para se enfatizar palavras específicas. Quanto ao ritmo, o grupo entoacional 2 permitiria uma pausa de continuidade (marcada pelas reticências); as demais deveriam seguir em ritmo direto e consistente.

1. Eu acho essa palavra uma das mais FORTES e mais PERIGOSAS da língua portuguesa.

2. Porque NINGUÉM pode afirmar com PROPRIEDADE ... que NUNCA vai agir de uma certa forma.

3. O futuro VIVE nos pregando PEÇAS!

Os exemplos abaixo ilustram as leituras feitas por dois alunos participantes da pesquisa, cada um configurando um nível final distinto de expressividade oral.

Na primeira amostra, o aluno seguiu os grupos entoacionais maiores do texto original, ou seja, o fraseado coincide com o do texto original; também chega a demonstrar alguma expressividade e a enfatizar palavras, como no grupo entoacional 3. No entanto, o leitor quebra bastante a fluidez do ritmo, efetuando pausas em locais inadequados (ex., entre essa palavra ... uma das e perigosas ... da língua portuguesa) e misturando leitura rápida com lenta. 
1. Eu acho [que] essa palavra ... uma das mais fortes e mais perigosas ... da língua portuguesa.

2. Porque ninguém pode afirmar com propriedade que nunca vai agir ... de uma certa forma.

3. O futuro vive nos pregando ... PEÇAS!

O segundo exemplo mostra a dificuldade de um aluno nas três dimensões. Sua leitura é monotônica, ou seja, sem qualquer variação na voz, e nenhuma ênfase é empregada. Em relação ao fraseado, o aluno ainda não consegue reconhecer as fronteiras entre grupos entoacionais como, por exemplo, em $o$ futuro vive nos pregando peças, transformado em duas unidades sintáticas, marcadas pela entonação dada na leitura. Também há várias interrupções em lugares inadequados, quebrando o ritmo. No geral, sua leitura exibe pouco esforço para fazer o texto soar como língua natural, sem qualquer expressão do significado.

1. Eu acho essa palavra uma mais forte e mais perigosas da lingua portuguesa.

2. Porque ninguém ... pode afirmar com ... proprieda:de ... que nunca vai agir de uma ce-certa forma.

3. O futuro ... vive nos pregando.

4. Peças.

Dessa forma, percebe-se que a escala multidimensional contempla, objetiva e separadamente, as três importantes dimensões. Ao mesmo tempo, as pontuações individuais conseguem chegar a um nível único de expressividade oral, o qual demonstra a forma como o aluno utiliza os recursos prosódicos da língua falada durante a leitura. A seção seguinte apresenta os resultados obtidos com as análises das 126 leituras coletadas.

\section{Resultados e discussões}

Com base nos dados coletados e na escala multidimensional, foram organizados primeiramente os resultados das escolas pesquisadas, demonstrando o nível de fluência em expressividade oral no qual seus alunos se encontram. O gráfico 1 traz esse quadro comparativo, onde se observa que a maioria 
dos alunos encontra-se no nível de leitura pouco fluente (entre 2,1 e 3); a escola 03 foi a com pior desempenho, alcançando uma média geral de 1,5 (nível não fluente). Já a escola 01, foi a única a atingir o nível de fluência, embora tenha ficado com a média mínima desse nível $(3,1)$.

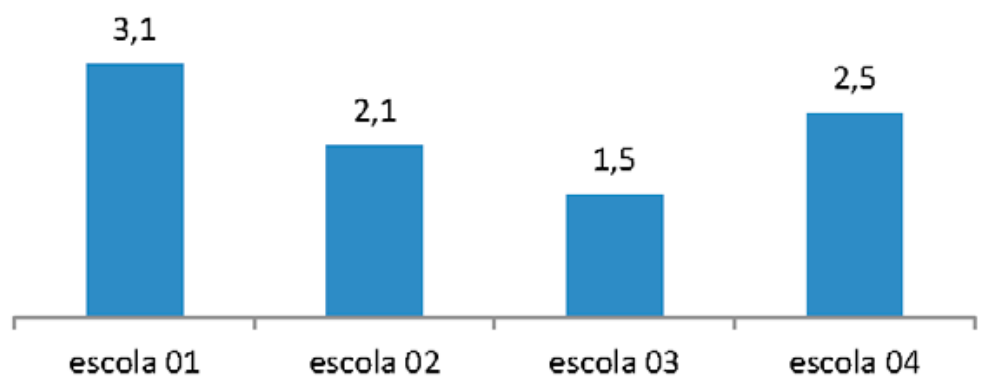

Gráfico 1: Nível final de expressividade oral por escola. Fonte: Projeto Fluência em leitura, 2013.

O próximo gráfico mostra os resultados, também por escola, do desempenho geral dos alunos nos três níveis finais: fluente, pouco fluente e não fluente. Em conformidade com o gráfico anterior, a escola com o melhor desempenho foi a escola 01, com concentração dos alunos nos níveis 'fluente' e 'pouco fluente'; nenhum aluno foi classificado como não fluente. As escolas 02 e 03, por outro lado, apresentam maior concentração dos alunos no 'nível não fluente', mas a escola 02 ainda tem uma parcela de alunos fluentes; a escola 03, ao contrário, tem a maioria de seus alunos no nível não fluente, com uma minoria de pouco fluentes. A escola 04 está com a distribuição dos alunos mais ou menos equilibrada, mas a maioria deles ainda não atingiu o nível adequado de leitura expressiva. 


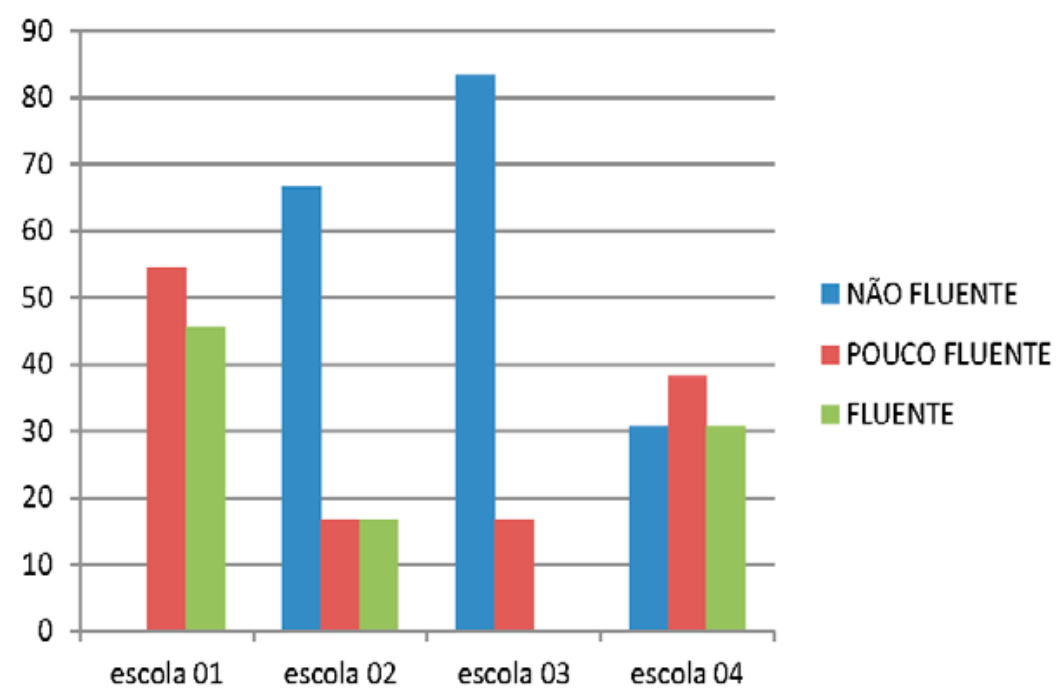

Gráfico 2: Gráfico comparativo das dimensões por escola. Fonte: Projeto Fluência em leitura, 2013.

Esse quadro é preocupante, principalmente porque se trata de um nível escolar $-2^{\circ}$ ano do ensino médio - no qual os alunos todos já deveriam ser plenamente fluentes, pelo menos desde o ensino fundamental (RASINSKI et al., 2005), pois essas habilidades emergem cedo na vida escolar da criança (CHALL, 1983). Mas o que se verifica é que, em geral, os alunos têm muita dificuldade em empregar, na leitura, a naturalidade da fala. Na maioria das vezes, oscilam entre leitura expressiva e inexpressiva, rápida e lenta. Eles exibem algum domínio da pontuação e da sintaxe do texto, mas ainda não monitoram completamente os equívocos ao agrupar palavras em unidades maiores de significado, pausando ou estabelecendo fronteiras entoacionais em locais indevidos; há também poucos ajustes na entonação de modo a refletir sua própria interpretação do texto.

A vantagem desse tipo de avaliação é que ela pode determinar em qual(is) aspecto(s) prosódicos da leitura o alunado apresenta maior dificuldade, o que pode fazer uma diferença enorme quanto à instrução da leitura nas escolas.

Nossa pesquisa constatou que todas as escolas se comportam da mesma maneira quanto às três dimensões: baixo desempenho em entonação e ênfase, seguido do fraseado e, por último, do padrão rítmico, conforme mostrado no gráfico 3 abaixo. 


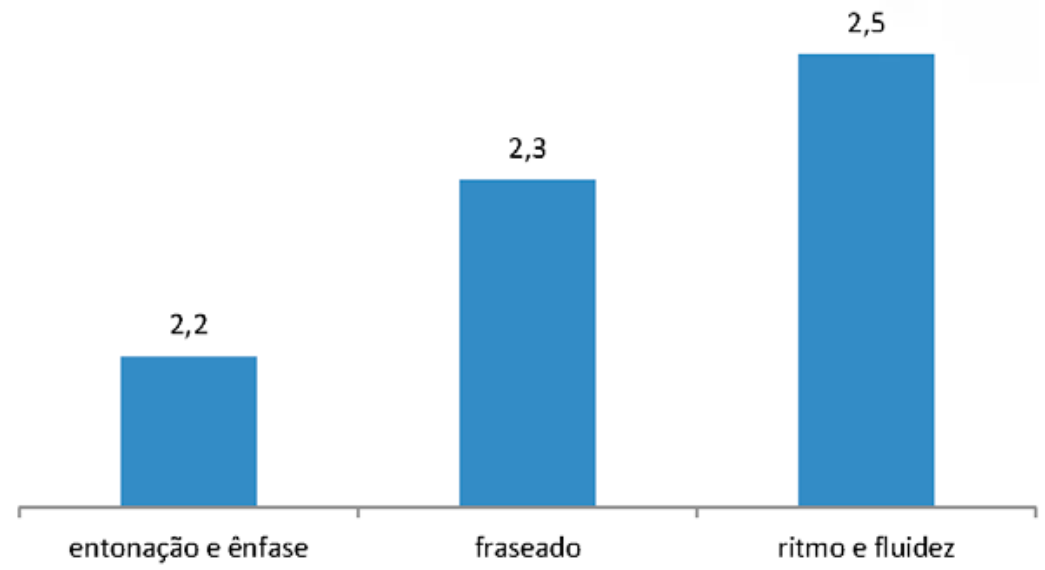

Gráfico 3: Média da pontuação dos alunos por dimensão. Fonte: Projeto Fluência me Leitura, 2013.

Esses resultados demonstram que os alunos ainda não alcançaram um nível minimamente aceitável de fluência. Acredita-se que esta pode ser uma das causas da estagnação no processo de proficiência em leitura, gerando um acúmulo de falhas que terão consequências em níveis mais elevados, principalmente o da compreensão. Como Paige et al. (2012, p. 69) ressaltaram, "estudantes que leem com expressividade apropriada em leitura oral tendem a ter uma melhor compreensão."

Se as diferenças entre as dimensões são pequenas em cada escola, entre as escolas essas diferenças são bem acentuadas, indicando uma heterogeneidade significativa no desempenho dos alunos de cada uma delas. O gráfico 4 traz essa comparação. 


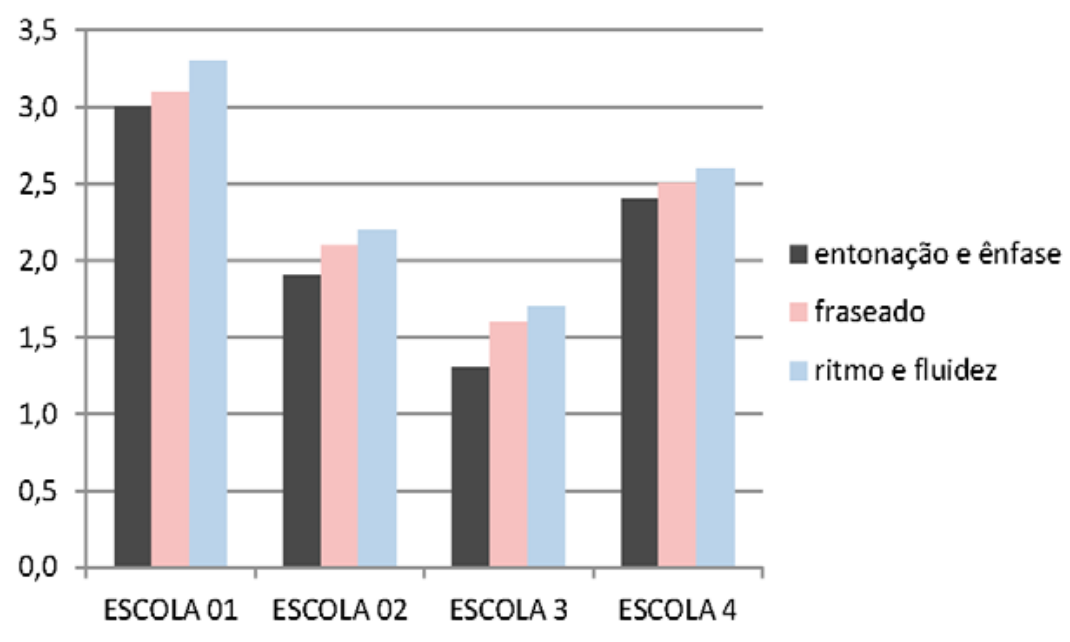

Gráfico 4: Distribuição das médias por dimensão. Fonte: Projeto Fluência me Leitura, 2013.

Na escola 01 , os alunos alcançaram em média 3,0 pontos ou mais nas três dimensões - isto é, nível fluente; mas os alunos da escola 03 ficaram abaixo de 2,0 pontos - nível não fluente. Nessa escola, a maioria dos alunos participantes exibe uma leitura monotônica e inexpressiva, sem um padrão rítmico consistente. Também não dirigem muita atenção às fronteiras de frases ou sentenças, agrupando as palavras de forma inadequada, com sérios prejuízos ao significado global do texto; a autocorreção tende a ser rara ou completamente ausente. Essa escola necessita, com certa urgência, que seus alunos sejam submetidos a um programa de intervenção para melhorar a fluência na leitura.

O último gráfico resume a distribuição global do desempenho dos alunos quanto ao nível final de expressividade oral de leitura desses 42 alunos. Observa-se uma concentração acentuada dos alunos no nível 'sem fluência' prosódica (41\%), contra $32 \%$ com pouca fluência, e somente $27 \%$ no nível fluente. 


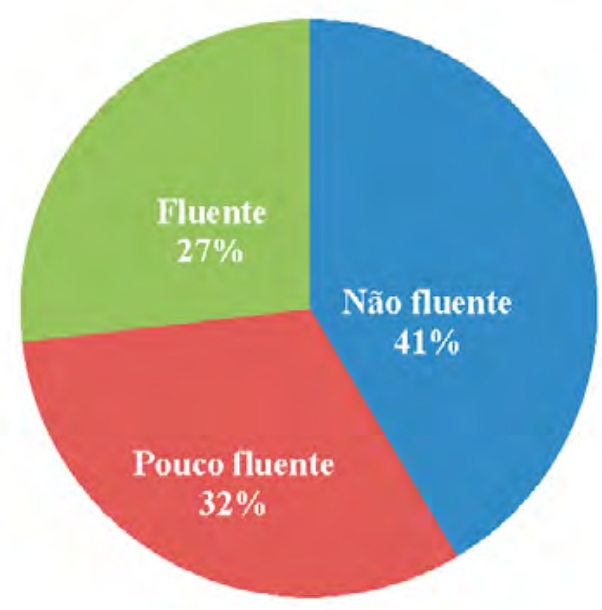

Gráfico 5: Distribuição dos alunos por nível de expressividade oral.

Fonte: Projeto Fluência em Leitura, 2013.

\section{Conclusão}

A prosódia demonstrada na leitura é comprovadamente uma boa indicação de que a criança está ou não se tornando um leitor proficiente (STANOVICH, 1980; RASINSKY, 1990; JENKINS et al., 2003). Afinal, um agrupamento sintático apropriado das palavras, com entonação, ênfase e ritmo adequados, faz com que os leitores elevem, e reflitam na leitura, sua própria interpretação da passagem, uma relação presente não só na leitura oral, mas também na leitura silenciosa (PINNELL et al. 1995; FUCHS et al., 2001; STAHL; KUHN, 2002, entre outros). Os resultados apresentados neste estudo apontam para uma grave deficiência no ensino da língua materna do ensino médio: a maioria dos alunos ainda não alcançou um nível minimamente aceitável de fluência. Como diminuir ou prevenir essa deficiência? Primeiramente, identificando as dificuldades. Há maneiras fáceis e precisas para determinar o que é "ler bem" ou "ler mal": basta ouvir o aluno lendo, por um minuto. 


\section{REFERÊNCIAS}

ABAURRE, M.L.M.; ABAURRE, M.B.M.; PONTAURA; M. Português: contexto, interlocução e sentido. São Paulo: Editora Moderna, 2008.

ADAMS, M.J. Beginning to read: Thinking and learning about print. Cambridge, MA: The MIT Press. 1990.

ALLINGTON, R.I. Fluency: The negledted reading goal. The Reading Teacher, n. 37, p. 556-561. 1983.

CAGLIARI, L.C. Da importância da prosódia na descrição de fatos gramaticais. In: ILARI, I. Gramática do Português Falado: níveis de análise linguística. Campinas: Editora da UNICAMP, 1992.

CHAFE, W. Punctuation and the prosody of written language. Written Communication, v. 5, n. 9, p. 395-426. Out. 1988.

CHALL, J. S. Stages of reading development. New York: McGrawHill Press, 1983.

DENO, S.L. Curriculum-based measurement: The emerging alternative. Exceptional Children, n. 52, p. 219-232. 1985.

DOWHOWER, S.L. Speaking of prosody: fluency's unattended bedfellow. Theory into Practice, vol. 30, n. 3, p. 158-164. 1991.

FOUNTAS, I.C.; PINNELL, G.S. Teaching for comprehending and fluency: Thinking, talking, and writing about reading, K-8. Portsmouth, NH: Heinemann, 2006.

FUCHS, L., FUCHS, D., HOSP. M., \& JENKINS, J. Oral reading fluency as an indicator of reading competence: A theoretical, empirical, and historical analysis. Scientific Studies of Reading, n. 5, p. 239-256. 2001.

JENKINS, J.R.; FUCHS, L.S.; VAN DEN BROEK, P.; ESPIN, C.; DENO, S.L. Sources of individual differences in reading comprehension and reading fluency. Journal of Educational Psychology, n. 95, p. 719-729. 2003.

KUHN, M. R., \& STAHL, S. A. Fluency: A review of developmental and remedial practices. Journal of Educational Psychology, n. 95, p. 3-21. 2003.

LaBERGE, D.; SAMUELS, S.A. Toward a theory of automatic information processing in reading. Cognitive Psychology, vol. 6, n. 2, p. 293-323. 1974. 
NRP. National Reading Panel. Teaching children to read: An evidence-based assessment of the scientific research literature on reading and its implications for reading instruction [on-line]. 2000. Disponível em: http://www.nichd.nih.gov/ publications/nrp/ report.cfm. Acesso em: 10 ago. 2013.

PAIGE, D.D.; RASINSKY, T.V.; MAGPURI-LAVELL, T. Is fluent, expressive reading important for high school readers? Journal of Adolescent $\mathcal{E}$ Adult Literacy, vol.56 (1), set. 2012, International Reading Association, 2012, p. 67-76.

PINNELL, G.S.; PIKULSKI, J.J.; WIXSON, K.K.; CAMPBELL, J.R.; GOUGH, P.B.; BEATTY, A.S. Listening to children read aloud. Washington, D.C.: Office of Educational Research and Improvement, U. S. Department of Education. 1995.

RASINSKI, T.V. Assessing reading fluency. Pacific Resources for Education and Learning, Hawai'i: Honolulu. 2004. Disponível em: http://www.decd.sa.gov.au/ northernadelaide/ files/links/ assessing201_1.pdf. Acesso em: 20 ago. 2013.

RASINSKI, T.V. Investigating measures of reading fluency. Educational Research Quarterly, vol. 14, n. 3, p. 37-44. 1990.

RASINSKY, T.V; PADAK, N.D.; MCKEON, C.A.; WILFONG, L.G.; FRIEDAUER, J.A.; HEIM, P. Is reading fluency a key for successful high school reading? Journal of Adolescent $\mathcal{E}$ Adult Literacy vol. 49, n. 1, p. 22-27. 2005.

STAHL, S.A.; KUHN, M.R. Making it sound like language: Developing fluency. The Reading Teacher, vol. 55, n. 6, p. 582-585. 2002.

STANOVICH, K.E. Toward an interactive-compensatory model of individual differences in the development of reading fluency. Reading Research Quarterly, n. 16, p. 32-71. 1980.

ZUTTELL, J.; RASINSKI, T.V. Training teachers to attend to their students' oral reading fluency. Theory into Practice, v. 30, p. 211-217. 1991. 


\section{Abstract}

\section{Prosody and fluent reading}

Expressive reading is a way to show that the reader is making sense of the meaning of a text. Therefore, oral expression in reading can make a distinction between good and poor readers, but can also be used to monitor comprehension. Fluent readers incorporate prosodic features of spoken language (accent, height variations of voice, intonation, phrasing and pauses) while reading, making it sound as natural as possible. This research shows the evaluation of the three prosodic dimensions, intonation and emphasis, phrasing and pace, in readings done by 2 nd year high school students from four public schools in Belém, state of Pará. The results reveal a serious deficiency in the Portuguese language teaching in high school: most of the students have not reached a minimally acceptable level of fluency yet.

Keywords: Fluency. Oral expression. Reading. Evaluation of reading. 